\title{
LINEAR PROGRAMMING OPTIMIZATION OF NUCLEAR ENERGY STRATEGY WITH SODIUM-COOLED FAST REACTORS
}

\author{
JEWHAN LEE ${ }^{1}$, YONG HOON JEONG ${ }^{1 *}$, YOON IL CHANG ${ }^{1,2}$, and SOON HEUNG CHANG ${ }^{1}$ \\ ${ }^{1}$ Korea Advanced Institute of Science and Technology, Department of Nuclear \& Quantum Engineering \\ Guseong-dong, Yuseong-gu, Daejeon 305-701, Republic of Korea \\ ${ }^{2}$ Argonne National Laboratory \\ 9700 South Cass Avenue, Argonne, IL USA 60439 \\ *Corresponding author. E-mail : jeongyh@kaist.ac.k
}

Received January 10, 2011

Accepted for Publication April 04, 2011

Nuclear power has become an essential part of electricity generation to meet the continuous growth of electricity demand. A Sodium-cooled Fast Reactor (SFR) was developed to extend uranium resource utilization under a growing nuclear energy scenario while concomitantly providing a nuclear waste management solution. Key questions in this scenario are when to introduce SFRs and how many reactors should be introduced. In this study, a methodology using Linear Programming is employed in order to quantify an optimized growth pattern of a nuclear energy system comprising light water reactors and SFRs. The optimization involves tradeoffs between SFR capital cost premiums and the total system U3O8 price premiums. Optimum nuclear growth patterns for several scenarios are presented, as well as sensitivity analyses of important input parameters.

KEYWORDS : Linear Programming, System Optimization, Sodium-cooled Fast Reactor

\section{INTRODUCTION}

Nuclear power option has become an essential part of electricity generation to meet the continuous growth of electricity demand. Limited uranium resources and the problem of nuclear waste management have rekindled interest in Sodium-cooled Fast Reactors (SFRs). Many countries are considering the construction of SFRs, including China, India, Russia, France, and Japan. Upon this background, the fuel cycle strategy decision (i.e., when and how many SFRs to build) has emerged as an important issue.

There have been extensive studies involving economic analyses of Light Water Reactor (LWR) systems, whereas few analyses of SFR systems have been reported. Previous economic studies focused on capital cost estimation and most studies show that the capital cost of a SFR might be higher than the corresponding cost of a LWR [1]. From the viewpoint of the total fuel cycle, however, advantages related to waste management and uranium utilization may compensate the potentially higher SFR capital cost [2][3]. With proper optimization of the overall energy system, SFRs may result in better overall system economics on the basis of reduced uranium costs.
The objective of this study is to apply a system approach to quantify the uranium resource implications of the introduction of SFRs, namely, the tradeoffs between higher SFR capital costs and savings in uranium resources, and to optimize the reactor mix between LWRs and SFRs.

A modified version of ALPS (A Linear Programming System), originally developed by Hanford Engineering Development Laboratory (HEDL) [4] and modified by Korea Advanced Institute of Science and Technology (KAIST), was used to optimize the nuclear fuel cycle system. The modification was focused on simplifying the ALPS to evaluate the interplay between the uranium resources and SFRs. The system was assumed to consist of LWRs (as representative thermal reactors) and SFRs (as representative fast reactors).

\section{LINEAR PROGRAMMING OPTIMIZATION}

\subsection{Fuel Cycle}

The fuel cycle considered in this study is shown in Fig. 1. The fuel cycle begins with $\mathrm{U}_{3} \mathrm{O}_{8}$ purchase. The amount purchased can be determined by $\mathrm{U}^{235}$ and $\mathrm{U}^{238}$. 


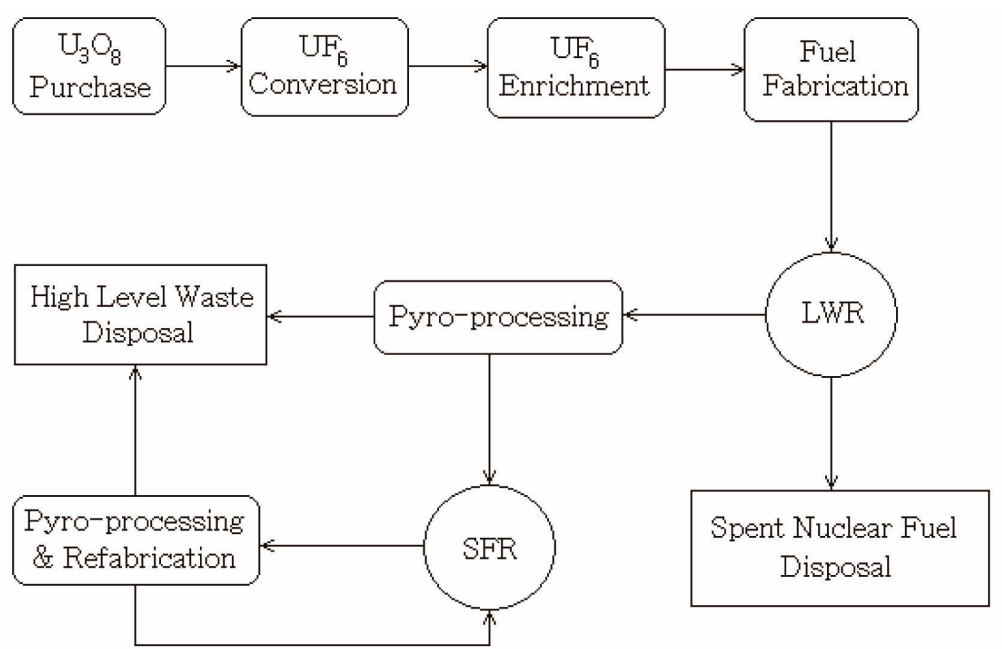

Fig. 1. Fuel Cycle of Nuclear System with LWRs and SFRs

With the known enrichment of LWR fuels and tails composition from input data, the ratio of feed to product can be calculated and thus $\mathrm{U}_{3} \mathrm{O}_{8}$ demand can be obtained. The $\mathrm{U}_{3} \mathrm{O}_{8}$ demand value is then converted into $\mathrm{UF}_{6}$ and enriched to the value specified by the LWRs. Next, the fabrication process follows and the cost is specified by year for each plant type and the fractional fuel loss is specified for each plant type.

The spent nuclear fuels from LWRs take one of two paths, either pyro-processing followed by use in SFRs or disposal. A small portion of fission products are produced in pyro-processing and are disposed as High Level Waste (HLW). The actinides and uranium recovered from pyroprocessing are used in SFRs. The spent fuels from SFRs are pyro-processed and recycled back into SFRs. Finally, the spent fuels from LWRs that are not pyro-processed for use in SFRs and the high level wastes from pyroprocessing are disposed in a geologic repository.

\subsection{Cost Function}

The total system cost to be solved and minimized by Linear Programming is described below. The total cost of the systems is divided into three components. The two main factors that Linear Programming optimizes are $N P(K, I)$ and $U(K, M)$. The first concern is the total cost of each plant and the second is the $\mathrm{U}_{3} \mathrm{O}_{8}$ cost. TCST(I) and $\operatorname{PRICE}(M)$ are the coefficients that must be assigned by inputs before the optimization process. Detailed descriptions of these inputs are provided in section 2.3.

$$
\begin{aligned}
Z= & \sum_{K}^{M E} \frac{1}{(1+D R)^{K}} \sum_{I}^{I P} \operatorname{TCST}(I) N P(K, I) \\
& +\sum_{K}^{M E} \frac{1}{(1+D R)^{K}} \sum_{M}^{N Q V P} \operatorname{PRICE}(M) U(K, M)
\end{aligned}
$$

$$
\begin{aligned}
& \text { where } Z \quad=\text { total discounted cost of the system } \\
& T C S T(I)=\text { total lifetime cost of plant type } I \text {, } \\
& \text { present worthed using discount rate } \\
& \text { DR } \\
& \operatorname{PRICE}(M)=\text { price of the } \mathrm{U}_{3} \mathrm{O}_{8} \text { at price level } M \\
& N P(K, I) \quad=\text { number of plants built during time } \\
& \text { step } K \text { of plant type } I \\
& U(K, M) \quad=\text { quantity of } \mathrm{U}_{3} \mathrm{O}_{8} \text { of price level } M \\
& \text { used during time step } K \\
& K=\text { index of time step } \\
& M E \quad \text { = number of time steps } \\
& I \quad=\text { index of plant type } \\
& I P \quad=\text { number of plant types } \\
& M \quad=\text { index of } \mathrm{U}_{3} \mathrm{O}_{8} \text { price level } \\
& N Q V P=\text { number of } \mathrm{U}_{3} \mathrm{O}_{8} \text { price level } \\
& D R=\text { discount rate }
\end{aligned}
$$

All costs are handled on a yearly basis and discounted from their time of occurrence and to the beginning of the first year. Therefore, any cost at the end of year $K$ would result in a discounted cost of $1 /(1+D R)^{K}$. The discount rate is taken as input data and different rates can be specified for specific time spans.

The assumption on $N P(K, I)$ is that the plant is built at the beginning of year $K$ and is shutdown at the end of year $K+K L I F E$. All fixed charge and amortization payments are assumed to occur at the end of each year. The fuel feed occurs at the beginning of each year and fuel discharge occurs at the end of each year.

\subsection{Coefficients}

\subsubsection{Total Plant Cost - TCST(I)}

Total plant cost consists of the 3 items described below. 


$$
\begin{aligned}
\operatorname{TCST}(I)=[ & (\operatorname{POW}(I) \cdot \operatorname{CAP}(I)) \\
& +\operatorname{OAM}(I)+\operatorname{FEXP}(I)]\left(\frac{(1+D R)^{K L I F E}-1}{D R(1+D R)^{K L I F E}}\right)
\end{aligned}
$$

where $\operatorname{TCST}(I)=$ total lifetime cost of plant type $I$

$P O W(I)=$ power of plant type $I$

$C A P(I)=$ annualized capital cost amortization of plant type $I$

$O A M(I)=$ operation and maintenance cost of plant type $I$

$F E X P(I)=$ fuel expenses of plant type $I$ except $\mathrm{U}_{3} \mathrm{O}_{8}$ cost

$D R \quad=$ discount rate

$K L I F E=$ plant life

The annualized capital cost amortization of each plant is calculated by the following equation.

$$
C A P(I)=I C A P(I) \frac{F C R(1+F C R)^{K L I F E}}{(1+F C R)^{K L I F E}-1}
$$

where $I C A P(I)=$ initial capital cost of plant type $I$

$F C R=$ annualized fixed charge rate

KLIFE = plant life

$I C A P(I)$ is an input parameter for each plant type, expressed in terms of $\$ / \mathrm{kWe}$. In the above equation, the capital cost is annualized using a fixed charge rate (FCR), which is typically higher than the discount rate (DR). The fixed charge rate can be an average cost of money between equity and debt financing and also includes any other applicable charges, such as taxes, insurance, etc. $O A M(I)$ is annualized operations and maintenance costs, expressed in terms of $\$ / \mathrm{kWe}-\mathrm{yr}$. $F E X P(I)$ is annualized fuel cycle costs, expressed in terms of $\$ / \mathrm{kWe}-\mathrm{yr}$. The cost $\mathrm{U}_{3} \mathrm{O}_{8}$ is excluded for LWRs. The cost of recycling is included in $F E X P(I)$ for SFRs.

\subsubsection{Uranium Price - PRICE(M)}

The cost of $\mathrm{U}_{3} \mathrm{O}_{8}$ is calculated as a piecewise-constant function of the total $\mathrm{U}_{3} \mathrm{O}_{8}$ consumed. Fig. 2 shows the price schedule of $\mathrm{U}_{3} \mathrm{O}_{8}$. The number of different $\mathrm{U}_{3} \mathrm{O}_{8}$ prices, or piecewise-constant terms, is an input parameter. In this study, three steps in the uranium price schedule are used and the input data are based on the IAEA Redbook (2009) [5]. The first step refers to the identified $\mathrm{U}_{3} \mathrm{O}_{8}$ resources and the second step is undiscovered $\mathrm{U}_{3} \mathrm{O}_{8}$ resources. The third step implies unlimited amounts.

The available amount at a certain price level may change according to the size of the nuclear system. For example, Fig. 3 shows the estimation of the available amount of $\mathrm{U}_{3} \mathrm{O}_{8}$ for Korea. The available amounts were scaled down based on the current market share.

\subsection{Constraints}

There are 5 types of constraints, as discussed below.

\subsubsection{New Capacity Equation}

The new capacity equation is required to calculate the plant buildup rate for each time step. The set of equations restricts the buildup of plants according to the electricity demand. The new capacity equation can be expressed as follows.

$$
\sum_{I}^{I P} P O W(I) N P(K, I)=C D(K)
$$

where $P O W(I)=$ power level of plant type $I$

$C D(K)=$ new capacity demand during time step $K$

$N P(K, I)=$ number of plants built during time step $K$ of plant type $I$

$I \quad=$ index of plant type

$I P \quad=$ number of plant types

$K=$ index of time steps

In addition, the replacement capacities are added to $N P(K, I)$ as the plants are retired at the end of their life in order to maintain the $C D(K)$.

\subsection{2 $\mathrm{U}_{3} \mathrm{O}_{8}$ Constraint}

In order to obtain the $\mathrm{U}_{3} \mathrm{O}_{8}$ price as a piecewiseconstant function of the cumulative $\mathrm{U}_{3} \mathrm{O}_{8}$ demand, two sets

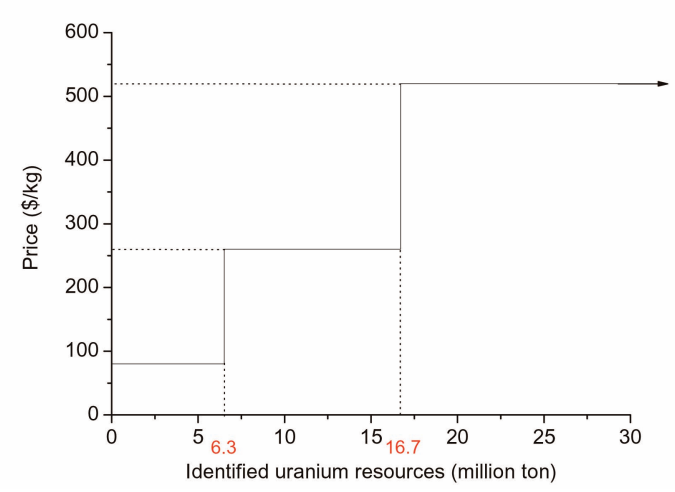

Fig. 2. $\mathrm{U}_{3} \mathrm{O}_{8}$ Price Schedule (Worldwide)

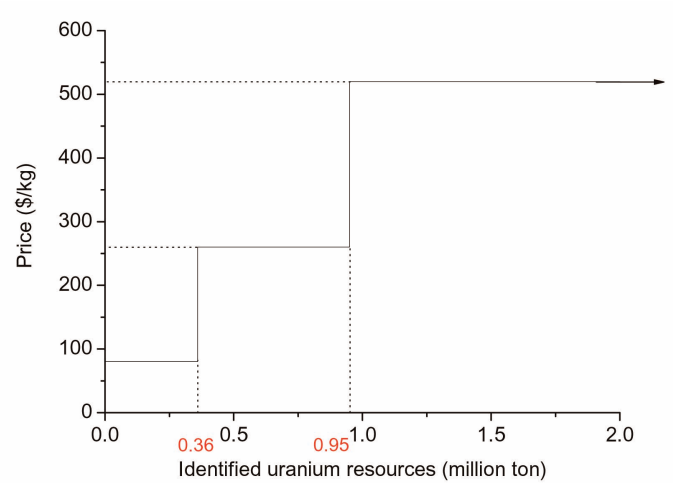

Fig. 3. $\mathrm{U}_{3} \mathrm{O}_{8}$ Price Schedule (Korea) 
of equations are required. In addition, $M-1$ inequalities are needed to keep the quantity of $\mathrm{U}_{3} \mathrm{O}_{8}$ in each price range within the stipulated bounds.

$$
\begin{gathered}
\sum_{K S}^{M E} \sum_{I}^{I P} U P(K S, K, I) N P(K S, I)=\sum_{M}^{N Q V P} U(K, M) \\
\sum_{K}^{M Y} U(K, M) \leq U L(M)-U L(M-1)
\end{gathered}
$$

where $U P(K S, K, I)=$ quantity of $\mathrm{U}_{3} \mathrm{O}_{8}$ used in year $K$ by plant type $I$ built in year $K S$

$N P(K S, I) \quad=$ number of plants built of type $I$ during time step $K S$

$U(K, M) \quad=$ quantity of $\mathrm{U}_{3} \mathrm{O}_{8}$ of price level $M$ used during time step $K$

$U L(M) \quad=$ limit of $\mathrm{U}_{3} \mathrm{O}_{8}$ available at price level $M$ and lower

$K S \quad=$ index of time steps

$M E \quad \quad=$ number of time steps

$M Y \quad=$ number of time steps

$I \quad=$ index of plant type

$I P \quad=$ number of plant types

$M \quad=$ index of $\mathrm{U}_{3} \mathrm{O}_{8}$ price level

$N Q V P \quad=$ number of $\mathrm{U}_{3} \mathrm{O}_{8}$ price levels (quantity vs. data points)

\subsubsection{Actinide Constraint}

The actinide constraint ensures that no SFRs are built without a sufficient amount of actinides for the startup of the plant. The constraint simply sets the available actinides in time step $K$ equal to the amount of available in time step $K-1$ minus the net consumption. Thus, one equation is required for each $K$.

$$
\begin{aligned}
A C T P(K)= & A C T P(K-1) \\
& +\sum_{K S}^{M E} \sum_{I}^{I P} A C T P 1(K S, K, I) N P(K S, I)
\end{aligned}
$$

where $\operatorname{ACTP}(K)$

$=$ actinides inventory at end of time step $K(A C T P(O)$ is an input parameter)

$A C T P 1(K S, K, I)=$ net actinides' inventory change during $K$ for a plant type $I$ built in $K S$

$N P(K, I) \quad=$ number of plants built of type $I$ during time step $K$

$K=$ index of time step

$K S \quad=$ index of time step

$M E \quad$ = number of time steps

$I \quad=$ index of plant type

IP $\quad=$ number of plant types

\subsubsection{Introduction Constraint}

The introduction constraints serve to limit the growth rate of nuclear plants. Such constraints can simulate the maximum buildup rate of a new technology plant (in this study, SFR).

$$
N P(K, I) \leq \operatorname{MAXPP}(K, I)
$$

where $N P(K, I)$

$=$ number of plants built of

$\operatorname{MAXPP}(K, I)$ type $I$ during time step $K$

$=$ number of additional plants that can be built in $\mathrm{K}$ over what already has been built to date

\section{RESULTS}

\subsection{Input Values}

The optimization process was performed several times for verification. The discount rate is set at $3 \%$ and the fixed charge rate for capital cost amortization is set at $10 \%$. In addition, the plant life for both LWRs and SFRs is assumed to be 60 years and the power level for both plant types is assumed to be $1000 \mathrm{MWe}$. The core type of SFR is particularly chosen to be a breeder type. The effect of adopting other core types will be covered in the sensitivity analysis section.

Values for coefficients are decided as follows. Parameters in TCST(I) are shown in Table 1. In particular, $I C A P(I)$ for LWR is assumed to be $\$ 3000 / \mathrm{kWe}$ and for SFR it is assumed as $\$ 3000 / \mathrm{kWe}+\alpha$, where $\alpha$ is a variable and is initially set to be $\$ 300 / \mathrm{kWe}$. The value for PRICE(M) is described in the previous section (Fig. 2 and Fig. 3).

\subsection{Case Result I - Worldwide}

The capacity demand, $C D(K)$, in the worldwide case can be assumed as given in Fig. 4. Here, the data are obtained from "Nuclear Century Outlook" of World Nuclear Association (WNA) [6] and the assumption is based on the average of high and low cases. The results of LP optimization are shown in Fig. 5. In this figure, SFR initially takes a small portion in 2020 and the portion greatly increases after 2050. Because of its technological immaturity, SFR was set to commence operation in the year 2020 and the number of SFRs was limited, as presented in Table 2. Many countries are planning their first commercial SFR by 2020 2030 and thus the limitation on the number of reactors was set to be 10 by the year 2030. Eventually, the technology will mature and

Table 1. Values for Various Input Parameters

\begin{tabular}{c|c|c}
\hline \multirow{2}{*}{ Parameter } & \multicolumn{2}{|c}{ Value } \\
\cline { 2 - 3 } & LWR & SFR \\
\hline ICAP(I) & $\$ 3000 / \mathrm{kWe}$ & $\$ 3000 / \mathrm{kWe}+\alpha$ \\
\hline OAM(I) & $\$ 120 / \mathrm{kWe}-\mathrm{yr}$ & $\$ 120 / \mathrm{kWe}-\mathrm{yr}$ \\
\hline FEXP(I) & $\$ 30 / \mathrm{kWe}-\mathrm{yr}$ & $\$ 45 / \mathrm{kWe}-\mathrm{yr}$ \\
\hline
\end{tabular}


Table 2. Introduction Constraint of SFR in Each Year

\begin{tabular}{c|c|c}
\hline Year & Cumulative SFR $(\mathrm{GWe})$ & Description \\
\hline 1990 & 0 & No SFRs \\
\hline 2010 & 0 & No SFRs \\
\hline 2030 & 10 & Many countries have plan of their first commercial SFR during this period. \\
\hline 2040 & 30 & In next 10 years, 20 more SFRs will be built. \\
\hline 2050 & 80 & In next 10 years, 50 more SFRs will be built. \\
\hline 2050 & - & Not constrained from 2050. Technology will mature to build additional SFRs without limit. \\
\hline
\end{tabular}

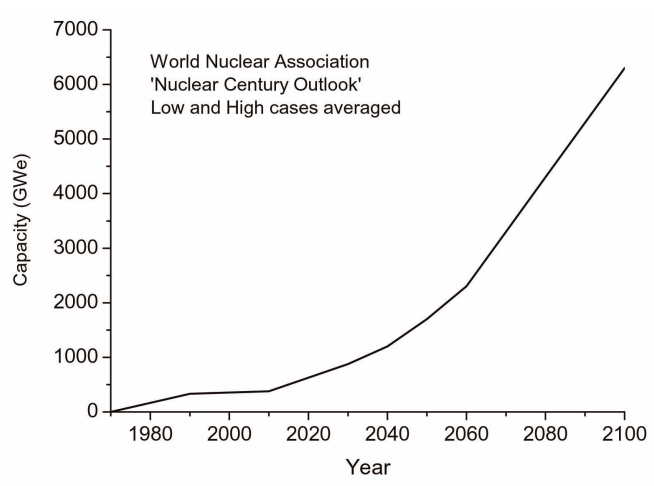

Fig. 4. World Capacity Demand in Future - Low and High Cases Averaged

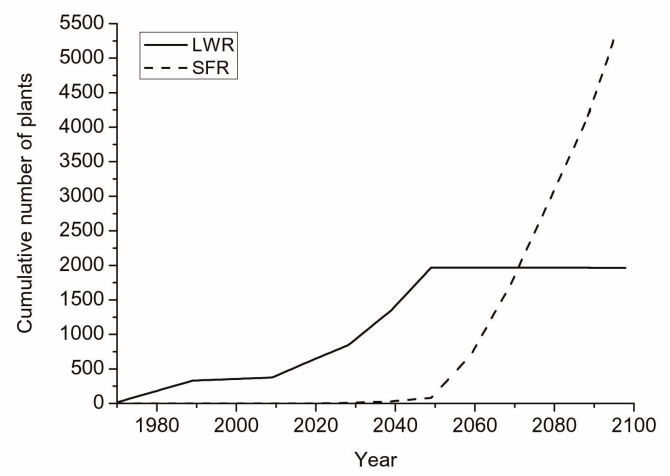

Fig. 5. Cumulative Number of Plant Build-up in World Case

demand will increase, resulting in more SFRs to be built. After 2050, technology and experience will have been accumulated and there will be no limit on the number.

It can be observed from the results that building of LWRs ceases in 2050 when the limit for SFR is removed (Fig. 5). Because of their strong advantage in uranium savings, SFRs will be built at the maximum rate. Fig. 6 compares the required uranium amounts between the LWR-only case and the optimized LWR+SFR case. As $\mathrm{SFR}$ is introduced at the maximum rate, the required uranium rate decreases.

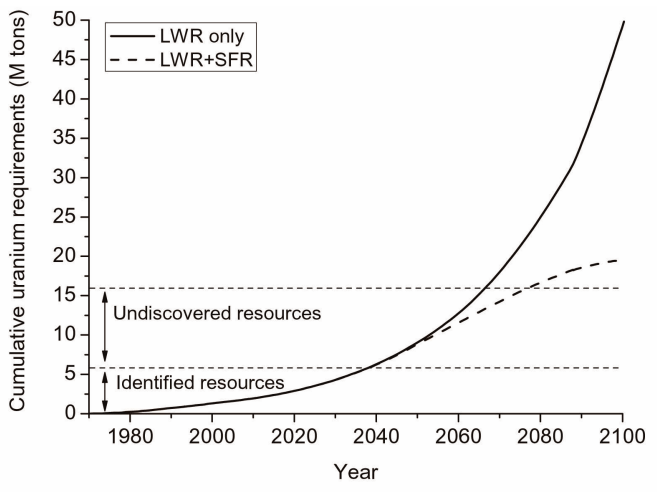

Fig. 6. Cumulative Uranium Requirements - World Case

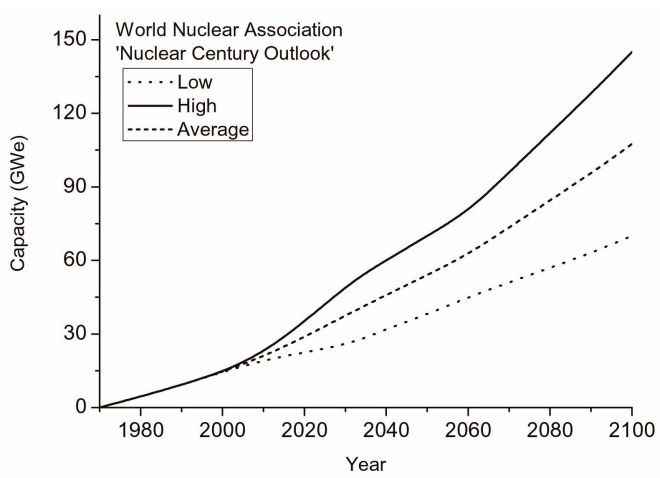

Fig. 7. Korea Capacity Demand in Future - Low and High Cases

\subsection{Case Result II - Korea}

The domestic case is analyzed from two perspectives, pessimistic (low case) and optimistic (high case) future. In the long-term R\&D plan of Korea, $15 \mathrm{GWe}$ more nuclear capacity is planned by 2030 , bringing the total capacity to 40 GWe. "Nuclear Century Outlook" [6] estimates the low and high cases, as presented in Fig. 7.

The cumulative number of plant build-ups for the domestic case with optimistic future (high case) and pessimistic future (low case) are shown in Fig. 8 and Fig. 9. Similar to the world case, the SFR introduction constraint 


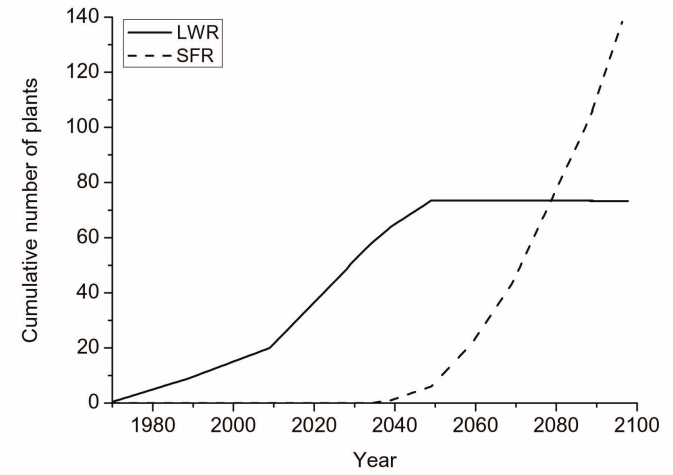

Fig. 8. Cumulative Number of Plant Build-up in Korea (High Case)

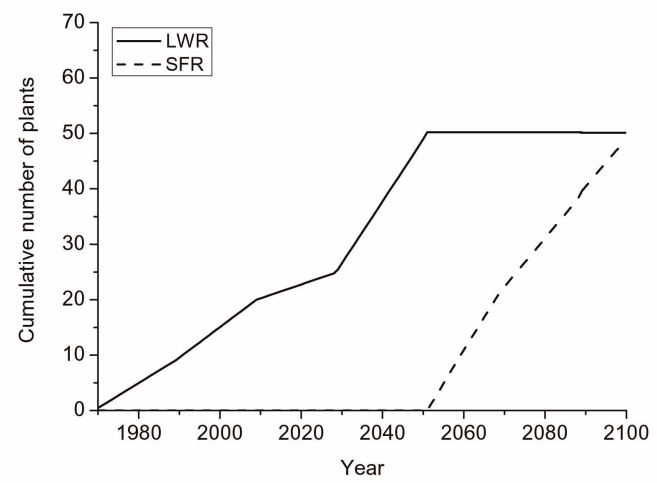

Fig. 9. Cumulative Number of Plant Build-up in Korea (Low Case)

was applied with consideration of the domestic situation. The first SFR was assumed to be ready/online(?) by 2030 , two more by 2040 , five more by 2050 , and no constraints afterwards. As seen in Fig. 8, the number of SFRs increases steadily following the introduction constraints. The results correspond closely with the world case (Fig. 5). However, for the low case of Korea, SFR introduction is delayed beyond 2050.

Required uranium amounts are shown in Fig. 10 and Fig. 11 for high and low cases in Korea, respectively. The increase in required uranium resources can pose a burden for Korea. However, similar to the world case, the LWR+SFR option assures benefits compared to the LWR-only case. Especially for the high case, the difference in 2100 is large enough to conclude that the SFRs have a competitive advantage.

\section{SENSITIVITY ANALYSIS}

The results are based on the input parameter assumptions. However, none of the input parameters are known to be reasonable values within any degree of certainty. Therefore, calculation of the most accurate

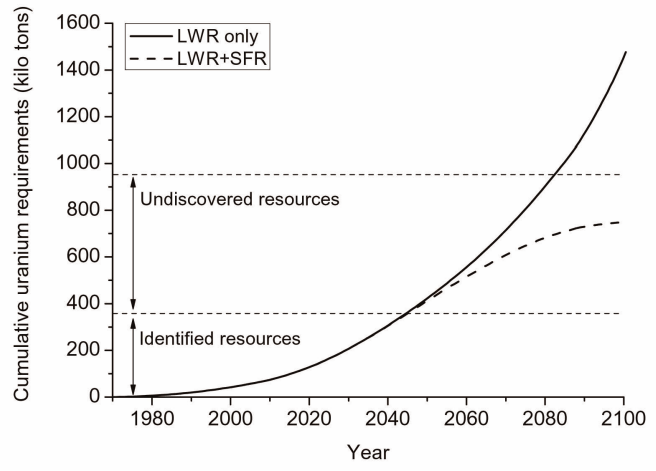

Fig. 10. Cumulative Uranium Requirements - High Case

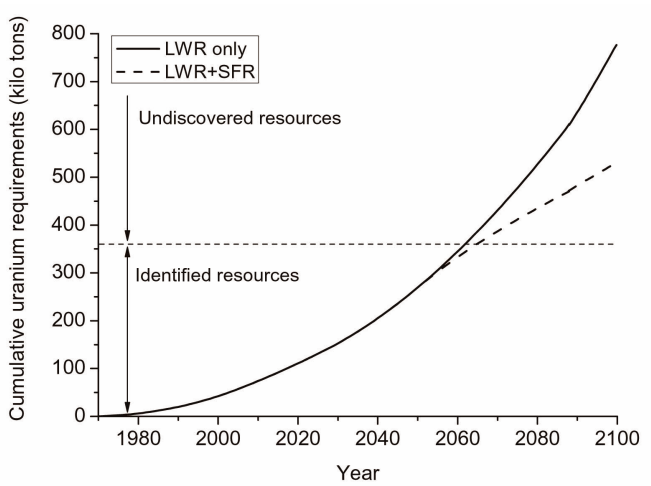

Fig. 11. Cumulative Uranium Requirements - Low Case

optimum point is not deterministic. Sensitivity analyses of the key input data are important for understanding the basic trends.

\subsection{Capital Cost}

One major obstacle that SFRs have to overcome is their economic viability, which strongly depends on their capital cost potential. The capital costs of initial SFRs will be higher than those of LWRs due to the first-of-akind costs. Since SFRs have not been commercialized yet, there is uncertainty in their ultimate capital costs. Therefore, in the present sensitivity study we treat the capital cost ratio between SFRs and LWRs as a variable in order to understand the role of the SFR capital costs. Fig. 12 shows the total system costs for various SFR/LWR capital cost ratios. The blue line implies the maximum SFR introduction without considering the cost. The lower shaded area represents the economical benefit and the upper area represents the economical costs when the SFRs are introduced at the maximum rate above the indifference point. As can be seen from Fig. 12, there is a limiting point in the optimum line beyond which SFR introduction in any year results in a higher system cost 


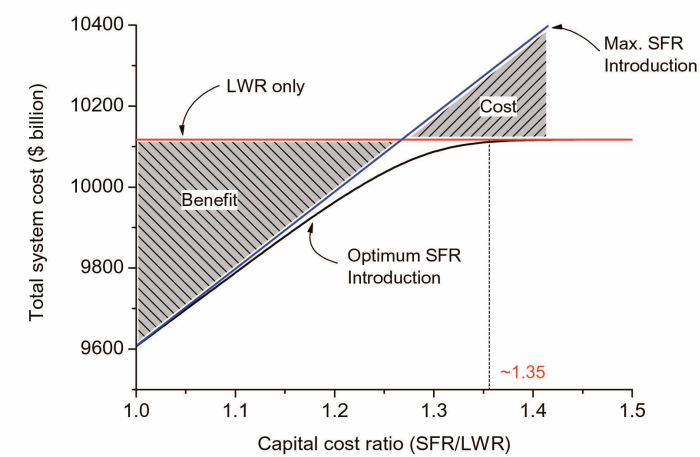

Fig. 12. SFR Capital Cost Effect on Total System Cost World Case

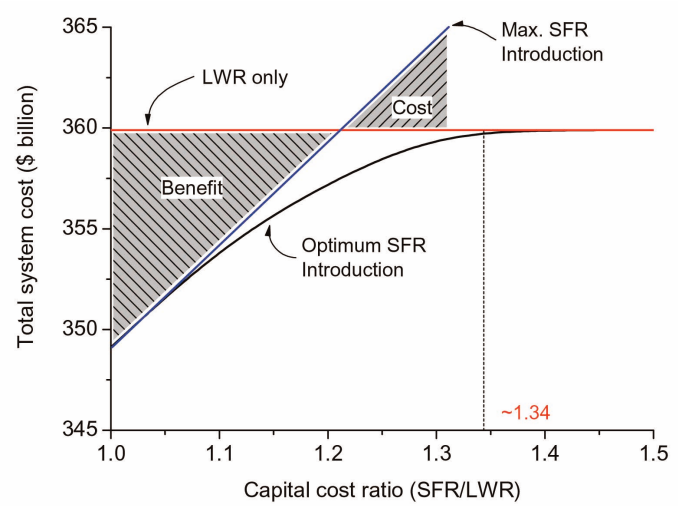

Fig. 13. SFR Capital Cost Effect on Total System Cost Korea High Case

than the LWR-only case. In this study, the limiting point of the capital cost ratio was found to be 1.35. Above this capital cost, the SFR loses its competitiveness to the LWR.

Fig. 13 shows the same aspect but the input values are based on the Korea high case. The limiting point was similar to the world case, i.e., about 1.34 . The costs have been scaled down while the allowable ratio is kept within the same level.

\subsection{Introduction Year}

The timing of the introduction of the first SFR has been a key issue in most SFR development programs. It is generally perceived that the first commercial SFR will be built in the time frame of $2020 \sim 2030$ at the earliest. Fig. 14 shows the effect of SFR introduction year on the total system cost for various capital cost ratios and LWRonly case. The SFR introduction constraint is maintained as given in Table 2 and the results are based on the worldwide case. It is shown that the later the SFR is introduced, the higher the total system cost will be. It can be concluded that for a wide range of SFR/LWR capital cost ratio as early introduction of SFRs as allowed results in a lower total system discounted cost.

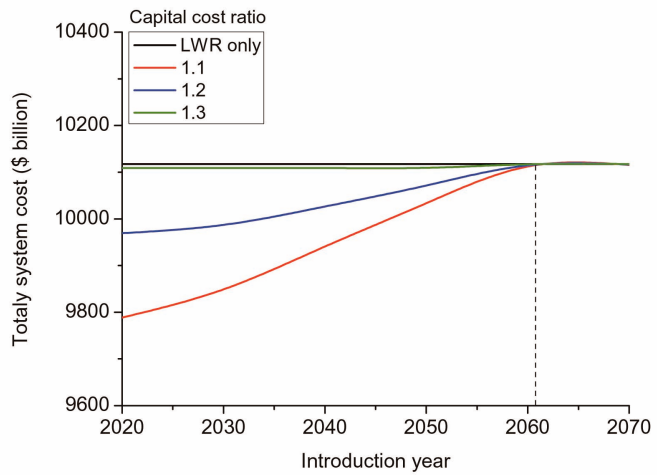

Fig. 14. SFR Introduction Year Effect to Total System Cost

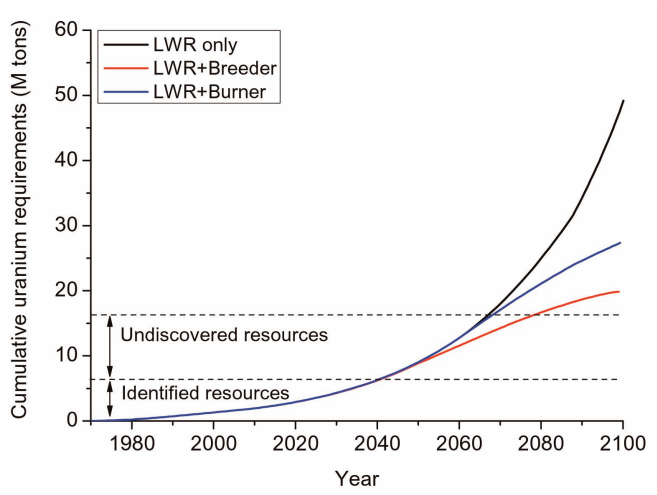

Fig. 15. Cumulative Uranium Requirements

\subsection{SFR Core Design}

Principally, the SFR core can be designed as breeder, self-sufficient, or burner types. Basically the core design is almost identical. If blankets are installed external to the core, it is classified as a breeder core. If reflectors replace blankets, then it is a burner type. A self-sufficient core can be achieved by appropriate amounts of blankets and reflectors. The corresponding fuel charge and discharge amounts as well as the fueling schedule are presented in Table 3 for each core design. Fig. 15 illustrates the effect of core design on cumulative uranium requirements. The results of break-even core type are abbreviated, because it shows the same trend as the breeder type. The small number of early SFRs during 2020 2050 does not influence the uranium requirements, as shown in Fig. 15, but the difference becomes more pronounced when the number of SFRs is unconstrained beyond 2050.

Fig. 16 represents the cumulative actinide amount produced by the reactors. The burner type SFR burns actinides and the amount greatly decreases, becoming almost zero in 2090. A gradual decrease is shown for the break-even type SFR despite that the core type is 'breakeven'. This is due to the initial loading amount, as 
Table 3. Actinide Mass Flow According to the SFR Core Types

\begin{tabular}{c|c|c|c}
\hline \multirow{2}{*}{ Phase } & \multicolumn{3}{c}{ Core type } \\
\cline { 2 - 4 } & Breeder & Break-even & Burner \\
\hline Initial loading (kg actinides) & \multicolumn{3}{c}{6000} \\
\hline Annual loading (kg actinides) & 1900 & 1500 & 1000 \\
\hline Annual discharge (kg actinides) & 7000 & 1500 & 4500 \\
\hline End of life (kg actinides) & & 6000 & \\
\hline
\end{tabular}

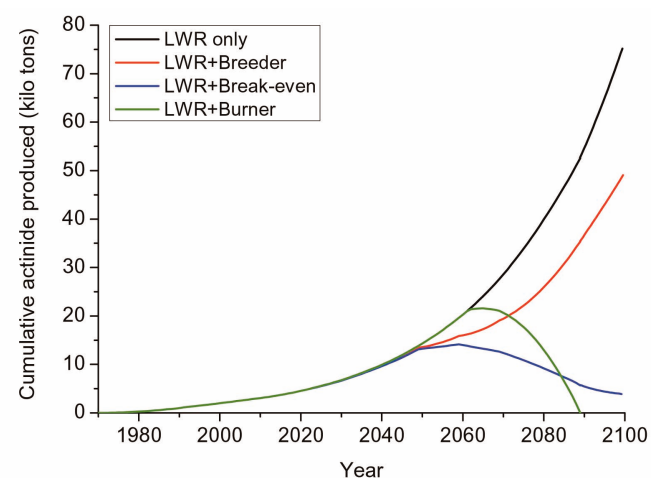

Fig. 16. Cumulative Actinide Amounts

described in Table 3. The sudden increase of newly operating SFRs after 2050 reduces the actinide amount. However, if the SFR build-up rate remains constant, this value is expected to rise slightly after 2110 when the reactor life ends. With the breeder type reactor, the amount increases, but not as much as the LWR-only case.

\section{CONCLUSION}

Since the outset of SFR development, the decision of when and how many SFRs to build has been a key issue. Previous studies have focused on a comparison of the electricity generation costs between SFRs and conventional LWRs. In such analyses, the impact of the SFR introduction on the overall uranium resource requirements cannot be quantified. In this study, a Linear Programming optimization model was employed to investigate the system effects of introducing SFRs to the growing nuclear energy system.

A parametric analysis indicates that even if the capital cost of SFRs is as much as 1.35 times that of LWRs there exist net benefits in the total system costs when SFRs are introduced as early as practically possible. This is due to the fact that the SFR introduction reduces the overall uranium requirements and thus less higher priced uranium resources are needed. This conclusion was reached for both the worldwide and the Korean nuclear capacity growth scenarios.

\section{ACKNOWLEDGMENT}

This work was carried out under the World Class University (WCU) Program supported by a National Research Foundation of Korea (NRF) grant (R33-10047) funded by the Ministry of Education, Science and Technology.

\section{REFERENCES}

[ 1 ] D.E. Shropshire et al., "Advanced Fuel Cycle Cost Basis", INL/EXT-07-12107, Idaho National Laboratory (2007).

[2] J.G. Delene et al., "ALMR Deployment Economic Analysis”, ORNL/TM-12344, Oak Ridge National Laboratory (1993).

[ 3 ] C.E. Till and Y.I. Chang, "Application of an LP Model to Breeder Strategy Studies", Proceedings of American Nuclear Society Topical Meeting on Computational Methods in Nulcear Engineering, Williamsburg, VA, Apr 23-25, 1979.

[4] R.W. Hardie et al., "ALPS, A Linear Programming System for Forecasting Optimum Power Growth Patterns", HEDLTHE-72-31, Hanford Engineering Development Laboratory (1972).

[ 5 ] IAEA OECD, "Uranium 2009: Resources, Production and Demand", OECD Nuclear Energy Agency and IAEA OECD (2010).

[6] World Nuclear Association, "Averting the Danger of Catastrophic Climate Change: Is the Nuclear Renaissance Essential”, WNA Nuclear Century Outlook (2010).

[7] IAEA, "Spent Fuel Reprocessing Options", IAEATECDOC-1587, IAEA (2008).

[8] Y.I. Chang and C.E. Till, "Economic Prospects of the Integral Fast Reactor (IFR) Fuel Cycle", International Conference on Fast Reactors and Related Fuel Cycles (FR' 91), Kyoto, Japan, Oct. 28-Nov. 1, 1991.

[9] E.A. Hoffman, "Estimated Cost for Low Conversion Ratio Burners", ANL-AFCI-118, Argonne National Laboratory (2004).

[10] C.E. Boardman et al., "Economic Assessment of SPRISM Including Development and Generating Costs", Proceedings of the $9^{\text {th }}$ international conference on nuclear engineering (ICONE-9), Nice, France, 2000. 